\title{
Valuing the effects of urban road-network projects: a methodological proposal
}

\author{
A. Granà \\ Department of Road Infrastructure Engineering, \\ University of Palermo, Italy
}

\begin{abstract}
This paper proposes a methodology of valuation for the urban environment, trying to answer questions and problems deriving from new road installations, or functional requalifications in existing road infrastructures, in accordance with specific practices already well-known as Urban Impact Assessment (UIA).

More generally, the objective of the urban impact assessment consists in valuing the possibilities to localize urban installations, also considering both their economic and social effects, as well as identifying potential dangers to the environment, intended in a general sense. This kind of valuation distinguishes from the traditional environmental impact valuation (e.g., applied for extra-urban road projects), because it gives more importance to aesthetical aspects, such as visual impacts; also through simulation devices with reference to models of urban habitat, it introduces the concept of urban quality for integrating to environmental (and ecologic) quality in order to make the first screening for possibilities of installations into urban areas, considering the element of participation central and ever present. According to the above explained general object, the analysis and valuation methodology proposed in this paper is a tool expressible in a language that can be codified, but with the smallest possible content of strict quantifications and general predetermined physical constraints; as well, it can be able to allow the valuation of real situations (related to urban road installations) working creatively and using prudently procedures and algorithms. The result represents an exploratory study to objectify a process characterized by a strong subjective content in order that the proposed methodology assumes the role of constitutive component of the urban road-network project assessment, as security for comprehensive positive outcomes.
\end{abstract}

Keywords: urban impact assessment, road safety, performances. 


\section{Introduction}

When the urban space is subject of analysis, as regards new infrastructural installations and the forecast of effects that location and conversion choices are able to make, the definition of an explicit and shared decision-making system conflicts with the intrinsic unforeseeability peculiar to the evolution of complex contexts. Nevertheless, considering the urban growth process, principles, methods and procedures for valuing outcomes of urban transformations are essential, with the awareness that the project (from the planning level to the geometric design one), however it is quality, isn't able to warrant the achievement of prearranged purposes, as well as to avoid the generation of unfavourable externalities and to consider all the relations of influence made by the project implementation.

Starting from these reflections, also considering that procedures and methods for valuing effects of infrastructural projects have been devised right from a few years with rising interest both in natural environment and in built/anthropical one, the need to delineate specific methodologies for valuing effects of urban road-network projects is derived.

In general, the peculiar elements of an evaluation process are [1]: i) the measurement, as set of activities for pointing out the targets; ii) the control, as the review of the effectiveness (and the reliability) of tools and process phases; iii) the verification, as collection of informative data qualitatively and quantitatively functional; iv) the evaluation, or rather the explanatory analysis oriented towards the taking on of choices.

The impact evaluation, just why it isn't related to marketing forms, discovers in the evaluation principles a problem of great extent; as regards this, the main problems are the following: i) the effectiveness, or the suitability of evaluation results to the aims to pursue by means of the application of the impact evaluation; ii) the reliability, or the characteristic to provide steady results whoever is the analyst and to reproduce the same result during subsequent evaluations carried out by the same analyst; iii) the intertemporal and interspatial comparability, or the complex articulation that, in the use suiting to needs, can foresee the "overcoming" of some steps without the overall working is invalidated.

An obstacle to define an procedure for valuing effects of urban road-network projects, based on sound, reliable and univocal (as for issues) principles, is referable to the effort for objectifying a process characterized by a strong subjective content. Based on above considerations, the urban impact assessment is absolutely necessary on condition that it is considered as a decision-making tool forcing to make clear ways and reasons of a choice and following the project course also up to produce mitigation actions for correcting unwanted results. In this sense, as security for a positive result, the evaluation can assume the role of constituent for the project design if, for having a clear picture of current and possible facts, it considers both the need to look into all the feasibility conditions and to examine crucial elements characterizing new infrastructural projects (or functional requalifications of urban spaces). 


\section{Theoretical-methodological questions of the UIA}

Nowadays there are many methodologies, as alternative to traditional economic analysis, used to carry out both the analysis of new infrastructural projects (or requalifications of existing installations) and the evaluation of effects. The methodological scheme of the impact evaluation procedure well-known as "systematic global evaluation" is revised and shown in figure 1.

The objective of this model is to establish both the (steady and repeatable) basis for the design/evaluation of activities related to the elements that can be considered interacting together (and producing relations among them) and to suggest the choice of more effective techniques for carrying out specific evaluations within each project action. Even though the methodological scheme doesn't apply to all cases, it allows by its articulation to select one infrastructural project (or more projects) that will be the object of the detailed analysis, i.e. the real impact evaluation focused on the examination of the consistency and the effectiveness.

This examination is the Urban Impact Assessment that includes in the inside the social and economic desirability analysis, as regards the different project alternatives, and carries out the compatibility analysis, the evaluation of results and the forecast for the uses and the future (direct and indirect) effects.

Within the evaluation of infrastructural projects, a decision making tool, considering the consequences on the environment as influential and decisive elements for valuing the project feasibility (both for maximizing the public benefit and for minimizing unfavourable results), is the well-known environmental impact assessment (eia). The eia as proposed by EEC directives is organized as follows:

a) preliminary activities deputed to the project selection demanding eia and to the identification of the project changes to value;

b) activities of evaluation deputed to: i) the detection of environmental impacts made by the project on the existing situation; ii) the description and the measurement of impacts by means of specific indicators and the evaluation of the changes granted to select the design proposal; iii) the list of the impacts and the choice of the mitigatory countermeasures. As an example, the procedural course of this phase is shown in figure 2;

c) consultation activities, involving authorities as regards request of authorization, as well as the parties concerned, and common participation;

d) decision-making activities, concerning the description of results and reasons have caused the decision.

In this sense, eia is the estimate of the effect extent on each environmental factor by means of a value judgement (or by a measurement), ascribing different weights to variables in relation to the impact extent. As an example, figure 3 shows the graph of impact evaluation for an urban commercial zone [3].

It thence follows that the urban impact assessment also needs already existing methodologies as it uses all the tools (for example, the eia ones as regards structure and procedural course) that allow to read, to organize and to check the available informations and the existing data. 


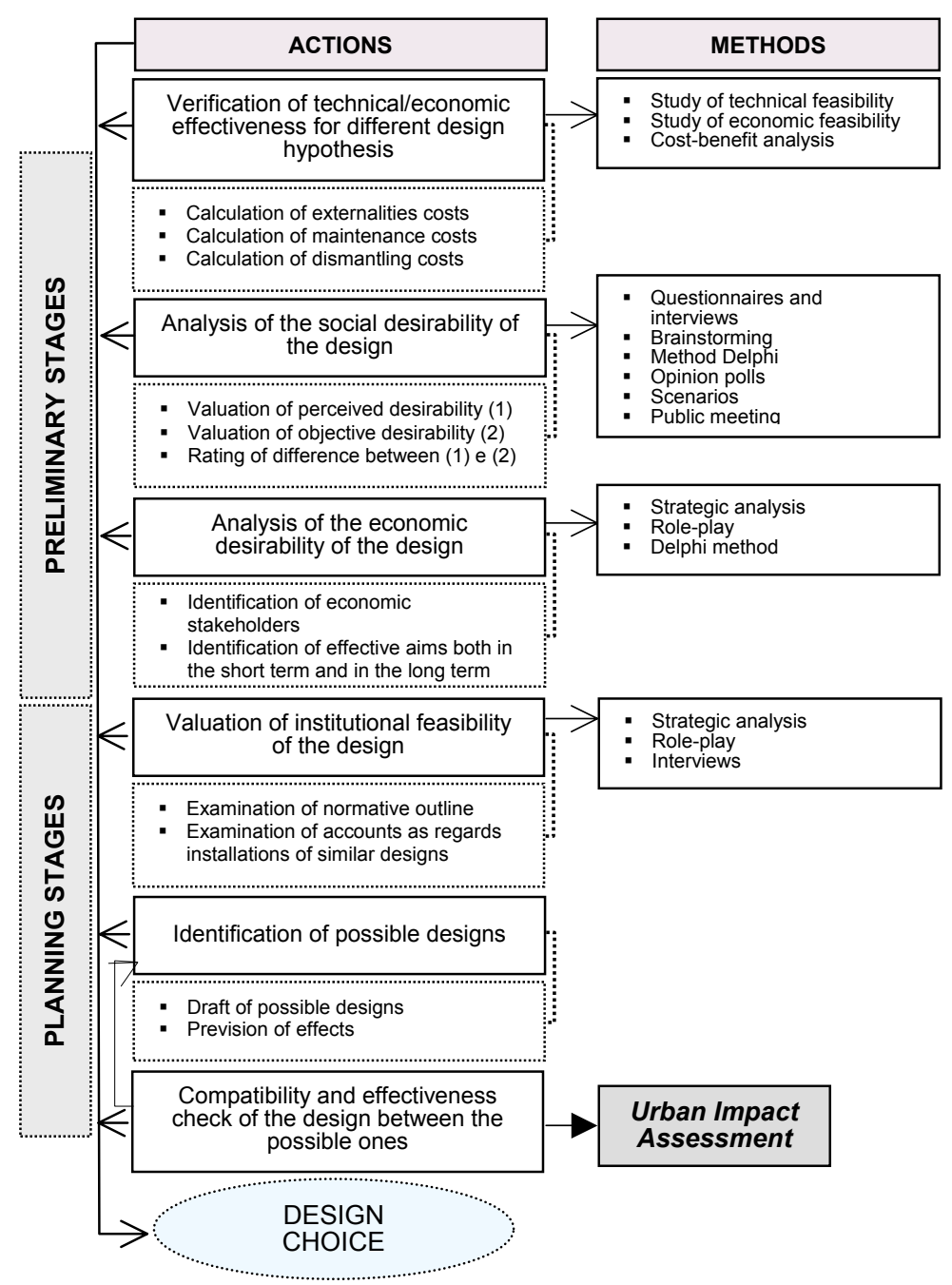

Figure 1: $\quad$ An example of urban impact assessment methodology [2].

Nevertheless, the UIA cannot be considered only an adaptation of other evaluation methodologies, why some phases and techniques have a greater weight as regards typical problems of the urban context. The UIA characterizes both for methodological aspects (i.e., the definition of urban quality factors, the visual and aesthetic impact assessment, the role of participation, etc.) and for the object of the evaluation.

From this, considering that the implementation of a procedure for valuing the impacts of road projects is correlated to the project contents, the peculiar elements of the urban road spaces and then the aspects of geometric design for urban roads have been explained in short before the methodology proposed is described. 


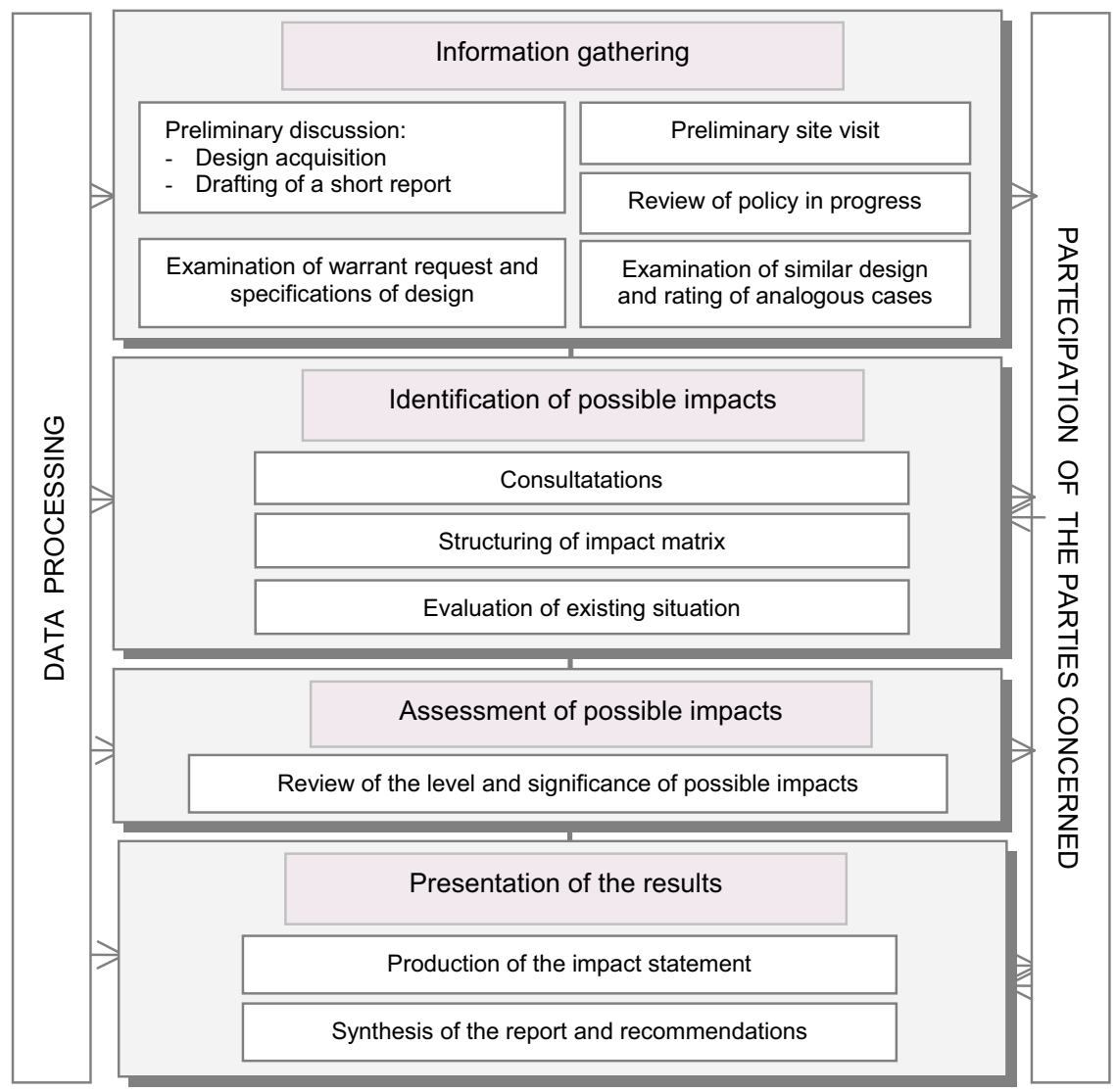

Figure 2: $\quad$ Procedural course of the assessment phase.

Primary
$\begin{gathered}\text { Shops } \\ \text { transfer } \\ \text { Affairs } \\ \text { transfer }\end{gathered}$

Figure 3: $\quad$ The impact of a new road within the trade zone of a city [3]. 


\section{The details of urban road geometric design}

The peculiarity of urban roads demands that the project approach, calling for different competences as regards the complexity of problems, maintains an unitary character; it has to consider the whole infrastructure life-cycle and to combine, from starting project activities, the right needs of construction, operational conditions and management.

The road, as a communication element, interacts to the environment passed through and becomes a place of subjects observing and using such places. The road theme always considers questions involving the layout (the link from the starting point to the destination) and relations among junctions (and functions) within different contexts; it also demands the knowledge of directives (rules and standards) concerning safety and traffic problems, environmental and aesthetical quality, etc.

So, within a town planning scheme, the road isn't only a route but becomes a road-network element; this requires both to put a hierarchical role down to it, as regards functions that have to be performed and the relation between junctions and traffic flow fluidity, and to put an architecture down to its cross section, as regards the recognizability of the feature-function relationship.

The geometric design and the evaluation phase cannot be out of road safety problems. From the road safety point of view, urban roads are less dangerous than extra-urban ones; this is true as regards crash consequences, why the urban space organization, the rapid series of junctions and traffic conditions (often close to congestion) limit speeds and reduce considerably crash dangerousness. This also influences clearly the death and injured rates [4] in use for highlighting crash phenomenon dangerousness: in probabilistic terms, urban crashes having fatal consequences are about three times and about five times lower than ones occur throughout freeways and other extra-urban roads respectively; the likelihood of user to be injured in urban crashes is in all cases lower regarding both freeways and other roads.

Nevertheless the perspective is very different if the extent and consequences of crash phenomenon are examined. Few data [5] can be useful for this purpose: a) the accident number in urban areas is more than $3 / 4$ of all crashes (they are 3 times and over 10 times greater than those on freeways and other extra-urban road respectively) and is three times higher than crashes occurred in other roads (ten times higher than freeways); b) the consequences of the accident phenomenon: deads caused by urban road crashes are about the half of all the deaths (every a hundred deads on urban roads correspond to about an half on main and provincial roads; less than $1 / 3$ on freeways).

\section{The difficult definition of "urban value"}

As is known, the value concept of a generic project component is linked to the utility assigned to the specific function chosen among those ones performed by the examined component, according to its total cost compatibly with available 
resources for producing and managing the life-cycle assumed for the road infrastructure.

For road constructions, the value concept is so closely connected to the efficiency and the effectiveness of road performances, or of those ones performed in a dynamic way by the examined component. So, considering that the efficiency and the effectiveness concern all the life-cycle of the road infrastructure, the geometric/functional design has to guarantee that starting performances persist in the time.

Based on these considerations, the evaluation can contribute to increase the value of a road infrastructure on condition that it is integrated in the project procedure and makes easy the value identification through a complete examination of the real functions, the prospects of the installation and the dimensional constrains.

From the seventies, a methodological approach, well-known as value engineering is developed progressively for road constructions and has transformed principles of urban road geometric design; this evolution has matched community transformations that, together with a more immediate participation of citizens to collective life, have reported an increasing respect for the environmental values and the life quality. So, the urban road project is the result of an interdisciplinary work characterized by different competences (road engineering, architecture, town planning, landscape painting, psychology, etc), sharing in the defining the geometric and functional features of road spaces.

This approach allows one to establish a scale to satisfy different needs [6], basing on road functional analysis [7], or on the recognition of needs, and on user expectations and motivations. Table 1 shows in short phases and corresponding activities of the value engineering.

Table 1: $\quad$ Articolazione dell'approccio di value engineering.

\begin{tabular}{|l|l|}
\hline phase & activity \\
\hline pre-trial & data collection, working team choice, definition of objectives \\
\hline functional & identification of requirements to satisfy \\
\hline inventive & research solutions by the formulation of functions and costs \\
\hline of valuation & function analysis \\
\hline development & selection and assessment of solutions \\
\hline of proposals & development and presentation of solutions \\
\hline
\end{tabular}

In the functional analysis of a specific road installation at least three furthermore classes of users need to be distinguished: each user (or road occupying) has a specific dimensional need (see table 2); constraints at sides, in general existing in urban areas, often request a priority choice among them [8]. 
Table 2: $\quad$ Classes of users.

\begin{tabular}{|c|c|c|c|}
\hline \multicolumn{2}{|c|}{ Users on the surface } & \multirow{2}{*}{$\begin{array}{l}\text { Users occupying } \\
\text { public property }\end{array}$} & \multirow{2}{*}{$\begin{array}{l}\text { Under-service } \\
\text { network }\end{array}$} \\
\hline Road users & consumers & & \\
\hline $\begin{array}{l}\text { Circulating and } \\
\text { stopped vehicles }\end{array}$ & $\begin{array}{l}\text { pedestrians and } \\
\text { reduced mobility } \\
\text { users, two-wheel } \\
\text { riders }\end{array}$ & Green spaces & $\begin{array}{c}\text { Energy and } \\
\text { telecommunication }\end{array}$ \\
\hline $\begin{array}{l}\text { Public transport (bus, } \\
\text { taxi, tram) and } \\
\text { delivery transport for } \\
\text { commercial products }\end{array}$ & Activities at sides & Urban equipment & $\begin{array}{l}\text { Aqueduct and city } \\
\text { sewer system }\end{array}$ \\
\hline $\begin{array}{c}\text { Security and } \\
\text { maintenance services }\end{array}$ & Public transport users & $\begin{array}{c}\text { Other services and } \\
\text { activities }\end{array}$ & $\begin{array}{l}\text { Pubblic lighting and } \\
\text { traffic control } \\
\text { systems }\end{array}$ \\
\hline
\end{tabular}

\section{The urban impact assessment proposed}

The methodological approach revises the procedure of Cecchini et al. [9] and proposes additional pieces allowing one to stress further aspects to value, as:

- visual impacts, considering that the urban context is strongly loaded with symbolic and perceptive values;

- impacts on performances, considering that urban geometric and functional design influences directly the integration of town parts and their development;

- impacts on traffic safety, considering that urban roads are characterized by different users including vulnerable ones (pedestrians, two-wheel riders, reduced mobility users, etc.).

For each impact figure 4 shows the principles by means of which a mark (or a judgement) can be ascribed to each basic element for carrying out the evaluation.

Completed the inventory phase, the analysis of places and related neighbourhood follows and for each above mentioned impact consists in: i) assigning a value to each basic element characterizing the road environment, basing on a scale of sensitiveness and quality variable for each impact; ii) classifying basic elements according to a relative hierarchic order; iii) bounding sites influenced by the project, in accordance with principles of morphologic, functional and typological consistency (this can vary regarding the analysed project); iv) creating, for sites influenced by the project, wired and transparent maps of synthesis in which low values (for sensitiveness and quality) are coloured by clear dyes and high values (for sensitiveness and quality) by dark dyes; v) valuing perceptions of users, that have to be reproduced on transparent maps too.

Maps drawn for each impact in accordance with the above mentioned principles of analysis can be used for choosing the project that, for features of location and morphology, corresponds to the need of containing all the possible impacts made by the same project on the environment passed through. The superimposition of maps so painted for each impact makes an only map showing impacts on the sites influenced by the project: in each impact map the very dark zones are characterized by high quality and sensitiveness to impacts and are 

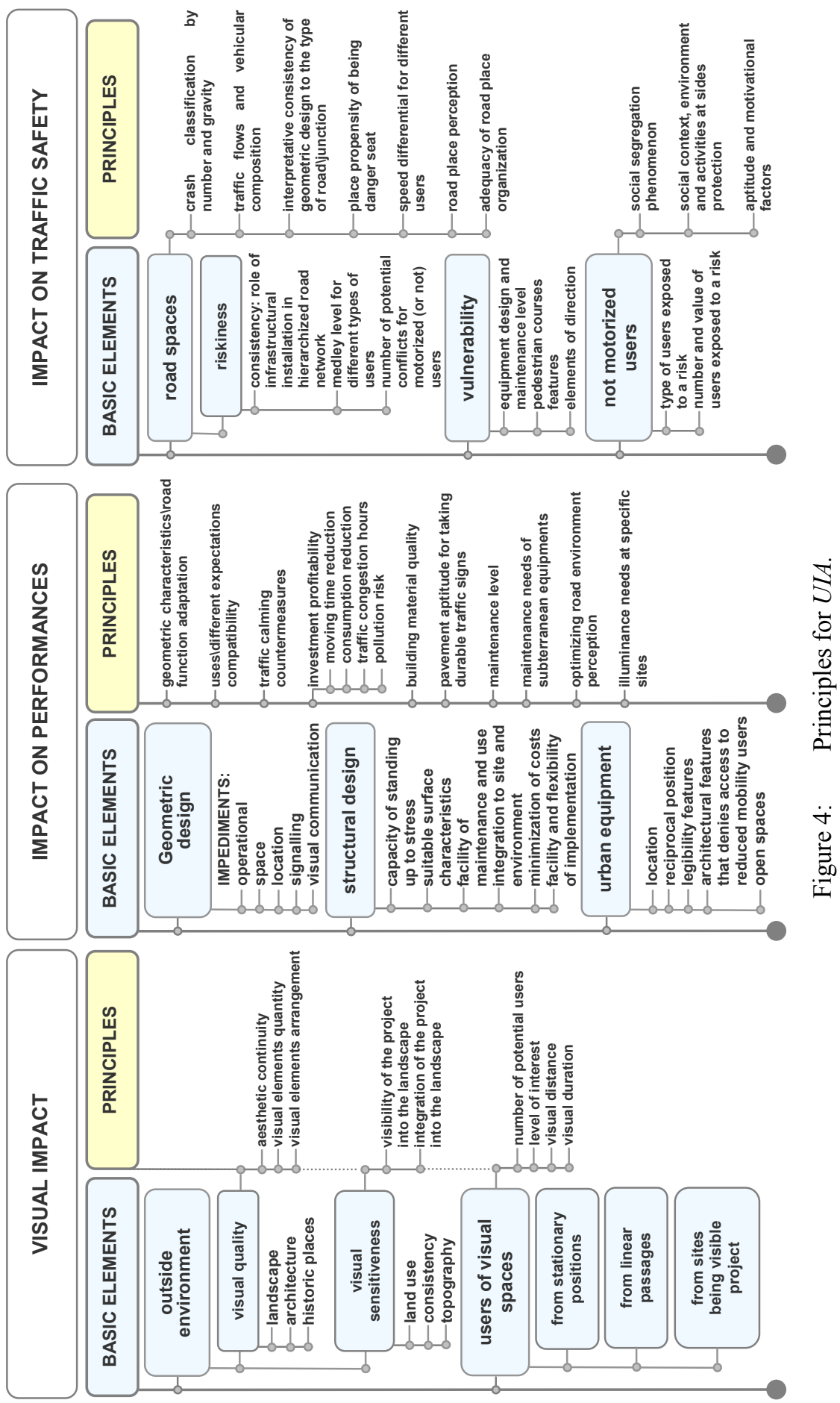

WIT Transactions on Ecology and the Environment, Vol 93, (c) 2006 WIT Press www.witpress.com, ISSN 1743-3541 (on-line) 
considered important by users. So the project has to be carried out only in the very clear zones resulting from the superimposition, characterized by a lower impact. The selected project, considering the location, the layout and the level of landscape alteration (from the construction level to the operation one), as well the contrast extent to the elements characterizing the environment passed through and the attraction of the project for users, represents a "compromise" solution, able to minimize the unfavourable effects of its installation.

In general, the evaluation also needs the simulation of the project for assessing impacts carried out on the environment passed through. The results of simulation, obtained by multimedia tools now available that allow fast to display the project into the modified environment, will show then to decision makers, to involved people and to groups of evaluation; this is for gathering remarks and indications on acceptance of impacts and/or on the possible implementation of mitigatory countermeasures to improve the project.

\section{Conclusions}

The methodological approach proposed for identifying, describing and assessing impacts carried out by infrastructural projects, both diffused (at the network and/or route level) and in specific point (at the junction and/or road situation level), has to be considered as a suggestion on possible elements to value and on principles for establishing quality judgements. This approach isn't a procedure to be applied mechanically; it is in fact free from rigid quantifications and general predetermined constraints and, being situated within the creative acting, can be intended as a combination of different methodological approaches (for example, methodologies used by VIA or specific methodologies for urban areas).

The methodological approach proposed in this paper is an overall view of easygoing suggestions for making clear the urban impact assessment. It isn't the path to carry out a technical calculation, but on the contrary, the outlined method can represent a tool applicable to real situations (related to urban road installations), able to combine qualitative and quantitative elements, to stimulate and organize the participation, not to give only a simple number.

The result has to be envisaged as an exploratory study to try both to objectify a process characterized by a strong subjective content and to integrate also in Italy the proposed methodology into the urban road-network project assessment, as security for comprehensive positive outcomes.

Moreover, the techniques have to be used considering that they are; in fact, tools to increase the awareness and the clearness are more useful than procedures for settling.

\section{References}

[1] Gori E., Vittadini G., Qualità e valutazione nei servizi di pubblica utilità. Etas, Milano (Italy), 1999.

[2] Clark B. D. et al., A manual for the assessment of major development proposals, HMSO, London, 1981. 
[3] Irer, Valutazione di impatto ambientale e calcolo economico, Ed. Angeli, Milano (Italy), 1984.

[4] Giuffrè O., Road safety in urban areas: a place of myths. Personal communication at SIIV Conference, 2 Dicembre 2005, La Sicurezza Stradale nell'Adeguamento della Viabilità Esistente, Catania (Italy).

[5] ISTAT Statistiche degli incidenti stradali - Anno 2004.

[6] Entretien des chausses urbaines. Guide méthodologique, Cetur, 1993.

[7] Analyse de la valeur. Guide pratique. Club des Concepteurs routiers. S.E.T.R.A., 1994.

[8] Aide à la conception de la voire urbaine par l'analyse fonctionnelle, Rapport d'étude Certu/Cete, 1997.

[9] Cecchini A., Fulici F., La valutazione di impatto urbano. Ed. Franco Angeli, Milano (Italy), 1994. 